This is the version of the article/chapter accepted for publication in World Development published by Elsevier : https://doi.org/10.1016/ j.worlddev.2019.104826 Accepted version downloaded from SOAS Research Online: http://eprints.soas.ac.uk/32182

C2020. This manuscript version is made available under the CC-BY-NC-ND 4.0 license http://creativecommons.org/licenses/by-nc-nd/4.0/

\title{
Small Development Questions are Important, but They Require Big Answers
}

Sara Stevano, SOAS University of London

\section{ss129@soas.ac.uk}

\section{Abstract}

The 2019 Nobel Prize for Economics awarded to the pioneers of Randomised Controlled Trials (RCTs) is a welcome acknowledgement of the fundamental challenge of poverty, but it should also be an opportunity to engage with the plurality of voices in development. A wealth of critiques of RCTs have highlighted how they neglect the structural conditions of poverty and are exposed to ethical and methodological flaws. Building on these critiques and primary research in Mozambique and Ghana, I engage with the debate on 'small versus big questions' - the RCT approach breaks big development questions into small ones in ways that jeopardise, according to critics, our understanding of development processes. I argue that small questions are also important, but, unlike what RCTs offer, they require big answers. Using the case of food, I show that we need approaches that can bridge micro-macro divides and highlight the structural underpinnings of daily practices.

\section{Acknowledgements}

I am thankful to Elisa Van Waeyenberge, Linda Calabrese and Susan Newman for their encouragement, the stimulating discussions and their helpful comments. Thanks also to Yana Rodgers for the editorial suggestions that helped improve this piece.

Nobel Prize winners Abhijit Banerjee, Esther Duflo and Michael Kremer received praise for their contribution to poverty alleviation. Theyemploy experiments to identify effective interventions andtheir work has elevated randomised controlled trials (RCTs) as the gold standard method for designing development policies. If the prize is a welcome acknowledgement of the fundamental challenge of poverty, it should also be an opportunity to engage with the plurality of voices that constitute development economics at a time when the discipline is grappling with the need to radically rethink the economic agenda on a global scale.

As summarised in a blogpost I wrote following the Prize announcement (Stevano, 2019), there is a wealth of critiques of RCTs. Some highlight that behavioural economics, on which RCTs rely, continues to draw on the rational agent, framed as the benchmark that boundedly-rational individuals need to aspire to. By focusing on the poor's individual behaviours, RCTs draw attention away from the structural conditions underpinning poverty and, furthermore, they are exposed to profound ethical issues as well as methodological flaws (e.g. Fine et al., 2016; Deaton and Cartwright, 2018). ${ }^{1}$

Building on these critical perspectives, here I engage with the debate on 'small versus big questions'. The RCT-pioneers and their critics concur that RCTs break down big development questions into small ones. There is also some overlap on what is considered to be a big question - What is the role of aid in development? How does trade/agricultural/industrial/fiscal policy contribute to development? (Banerjee and Duflo, 2012; Reddy, 2012). Instead, the small questions amenable to RCTs include What is the best way to ensure that children sleep under bed nets? What stands in the way of farmers' adoption of fertilisers? (Duflo et al., 2008; Banerjee and Duflo, 2012). The 'randomistas' argue that we need small tractable questions to address development issues based on evidence and through an acquired understanding of how the poor make decisions (Banerjee and Duflo, 2012). On the other hand, the critics contest that small thinking impairs our ability to understand development processes,

\footnotetext{
${ }^{1}$ See blogpost for additional references.
} 
and the hierarchy established among questions worth asking has pushed big questions into the background (e.g. Reddy, 2012; Rosenzweig, 2012).

I agree with the critics that the big questions cannot be bypassed and that the categorisation of some questions as not being amenable to rigorous evidence and prone to ideological interpretations is harmful. Yet, I would like to extend these perspectives by shifting the focus from the size of the questions to that of the answers. To do so, we need to consider the underlying thread linking questions to answers: the theoretical framework that informs the framing of questions, whether big or small, then the methods and, ultimately, the answers. I will return to the theory but let us consider an example first. Asking why farmers' adoption of fertiliser is low can be a legitimate question, if there is reason to believe that higher adoption could increase agricultural productivity, for instance. Duflo et al. (2008) ask this question for a group of Western Kenyan farmers and conclude that farmers would gain from higher investment in fertiliser but they fail to take advantage of higher returns because they are present-biased; small time-limited discounts on fertiliser purchase could correct this bias. However, this answer falls dramatically short of any understanding of the agro-ecological and political economy features of the context, which make the relationship between fertiliser use and increased yields dependent on the quality of the soil (Barrett and Carter, 2010). The poorest farmers have access to land of poor quality and face the most significant constraint to fertiliser adoption irrespective of any temporal bias (Ibid.) and important gender barriers also shape access to land and fertilisers (Quisumbing and Pandolfelli, 2010).

The problem lies in the underlying theory - behaviouralism based on methodological individualism that conceptualises individual behaviours as detached from economic structures and social relations of power. In Poor Economics, Banerjee and Duflo (2012) state that we need to investigate empirically how the poor perceive the relationship between income today and income tomorrow. There is essentially only a crucial way in which poverty shapes individual behaviours: through limiting cognitive abilities and disrupting the rationality of choice. Within this theoretical framework, the overall objective is to understand why the poor make choices that deviate from the optimal, as Rosenzweig (2012) points out, where the optimal is externally established - 'the poor resist the wonderful plans we think up for them' (Banerjee and Duflo, 2012: 35). It is then necessary to test what incentives can make the poor act less irrationally. Behind the pretence of humility, pragmatism and small questioning, we need to recognise the sweeping and reductive theorising on the psychology of the poor that underpins the design of RCTs.

Food is a case in point. In an article for Foreign Policy, which also appears in a revised version as a chapter of their book, Banerjee and Duflo $(2011 ; 2012)$ consider the problem of hunger. They wonder 'What if [...] they [the poor] eat the wrong kinds of food, depriving them of the nutrients needed to be successful, healthy adults? What if the poor aren't starving but choosing to spend their money on other priorities?' (Banerjee and Duflo, 2011: 69). They are preoccupied with understanding why the poor do not spend more on food and why, when more cash is available, they buy better-tasting food instead of maximising their nutrient intake. The analysis is also riddled with moralising remarks, such as the contempt expressed for a Moroccan villager complaining about the lack of food while having a TV at home, a note warning that we should not underestimate that life in a Moroccan village can be boring and the bewilderment at how much the poor spend on weddings and funerals, which completely misses the importance of reproducing social relations in contexts with minimal public provisioning. The conclusion is that food policy needs to encourage the poor to eat better because the problem is not the lack of food but the quality of food consumed and flawed spending priorities.

It is hard to believe how much is missing from this analysis and how misleading it is, as a result. For a start, there is extensive literature in nutrition, public health and social sciences documenting how 
today the main nutritional problem is malnutrition, which encompasses hunger, imbalanced diets and obesity (e.g. Hawkes 2006), which Banerjee and Duflo fail to acknowledge. Second, in their analysis there is not a single reference to the food industry or how food is produced and distributed. Of course, people spend extra cash on better-tasting food but the key question is what constitutes better-tasting food. The historical shifts in food production and trade lie at the root of people's economic and sociocultural relations to food. If we do not look at these trajectories, we would not be able to explain why in some parts of Africa people prefer maize and, more recently, rice imported from Southeast Asia over local grains, such as millet and sorghum (McCann, 2005). Today we cannot overlook the role of the food industry and how the rise of supermarkets as well as the use of informal channels of distribution make packaged and processed foods widely available, relative affordable and, aided by ubiquitous advertising, enticing too (Stevano et al., 2019). It is also important to consider how the price of healthy foods, such as fresh vegetables, is on the rise, while that of ultra-processed foods is stagnant or decreasing (Wiggins et al., 2015). Finally, food inequalities are also gendered, with research showing uneven intra-household food sharing at the expense of women (Harriss-White, 1997). Thus, how people spend money on food depends less on how they value the present versus the future and more on the structural features of agri-food systems and the associated economic, social and cultural relations to food, which change over time and are shaped by relations of power.

The framework underpinning RCTs cannot account for this complexity and, by implication, yields small, often misleading, answers to small and big questions alike. Small questions - for instance aimed at investigating food insecurity in a specific context or for a specific group - are essential. But it is also critical to recognise how phenomena observed at the micro-level are intertwined with macro processes and how the economic and the social interact in shaping daily practices. Mixed-method case studies, combining qualitative and quantitative data as well as multiple levels of analysis, are crucial to gain this understanding. To continue with the food example, quantitative data on individual diets, qualitative data on family practices, community customs and organisation of daily life in the studied context, food trade data and historical shifts in agricultural policies are all necessary to understand what people eat and what the problems are. Theoretical frameworks that allow for capturing the micro-macro interconnections, such as Ben Fine's system of provision and Susanne Freidberg's geography of provision, need to inform empirical analyses. We can and should ask small development questions, but we also need to provide big answers to them.

\section{References}

Banerjee, A., \& Duflo, E. (2011). More than 1 billion people are hungry in the world. Foreign Policy, (186), 66-72.

Banerjee, A. and Duflo, E. (2012). Poor Economics: A Radical Rethinking of the Way to Fight Global Poverty, New York: Public Affairs.

Barrett, C. B., \& Carter, M. R. (2010). The power and pitfalls of experiments in development economics: Some non-random reflections. Applied economic perspectives and policy, 32(4), 515-548.

Deaton, A., \& Cartwright, N. (2018). Understanding and misunderstanding randomized controlled trials. Social Science \& Medicine, 210, 2-21.

Duflo, E., Kremer, M., \& Robinson, J. (2008). How high are rates of return to fertilizer? Evidence from field experiments in Kenya. American economic review, 98(2), 482-88. 
Fine, B., Johnston, D., Santos, A. C., \& Van Waeyenberge, E. (2016). Nudging or fudging: The world development report 2015. Development and Change, 47(4), 640-663.

Harriss-White, B. (1997). Gender bias in intrahousehold nutrition in South India: unpacking households and the policy process. In Haddad, Hoddinott and Alderman (eds.) Intrahousehold Resource Allocation in Developing Countries. Models, Methods, and Policy, Washington DC: International Food Policy Research Institute, 194-212.

Hawkes, C. (2006). Uneven dietary development: linking the policies and processes of globalization with the nutrition transition, obesity and diet-related chronic diseases. Globalization and health, 2(1), 4.

McCann, J. (2005) Maize and Grace: Africa's encounter with a new world crop 1500-2000, London: Harvard University Press.

Quisumbing, A. R., \& Pandolfelli, L. (2010). Promising approaches to address the needs of poor female farmers: Resources, constraints, and interventions. World development, 38(4), 581-592.

Reddy, S. G. (2012). Randomise this! On poor economics. Review of Agrarian Studies, 2(2), 60-73.

Rosenzweig, M. R. (2012). Thinking Small: Poor Economics: A Radical Rethinking of the Way to Fight Global Poverty: Review Essay. Journal of Economic Literature, 50(1), 115-27.

Stevano, S. (2019) The randomistas won the 2019 Nobel Prize for Economics, will they also win the debate on development economics?' SOAS Blog, 16 October 2019, https://www.soas.ac.uk/blogs/study/randomistas-economics-nobel-prize/.

Stevano, S., Johnston, D., \& Codjoe, E. (2019). The urban food question in the context of inequality and dietary change: A study of schoolchildren in Accra. The Journal of Development Studies, 1-13.

Wiggins, S. et al. (2015). The rising cost of a healthy diet. Changing relative prices of foods in highincome and emerging economies, London, Overseas Development Institute (ODI). 